\title{
Asparagine synthetase is an independent predictor of surgical survival and a potential therapeutic target in hepatocellular carcinoma
}

\author{
B Zhang ${ }^{1,2,4}$, L-W Dong ${ }^{1,4}$, Y-X Tan ${ }^{1}$, J Zhang ${ }^{1}$, Y-F Pan ${ }^{1}$, C Yang ${ }^{1}$, M-H Li ${ }^{1}$, Z-W Ding ${ }^{1}$, L-J Liu ${ }^{1}$, T-Y Jiang ${ }^{1}$, \\ J-H Yang ${ }^{\star, 2}$ and H-Y Wang ${ }^{\star, 1,3}$ \\ ${ }^{1}$ International Cooperation Laboratory on Signal Transduction, Eastern Hepatobiliary Surgery Institute, Second Military Medical \\ University, 225 Changhai Road, Shanghai 200438, People's Republic of China; ${ }^{2}$ Department of Surgery, Eastern Hepatobiliary \\ Surgery Hospital, Second Military Medical University, 225 Changhai Road, Shanghai 200438, People's Republic of China and ${ }^{3}$ State \\ Key Laboratory of Oncogenes and related Genes, Shanghai Cancer Institute, Renji Hospital, Shanghai Jiaotong University School \\ of Medicine, Shanghai, People's Republic of China
}

Background: Asparagine synthetase (ASNS) is associated with drug resistance in leukaemia, and the function of this enzyme in the context of hepatocellular carcinoma (HCC) is not clear. In this study, the relationship between ASNS expression and clinical outcomes after surgical resection was investigated, and the therapeutic value of ASNS was also evaluated.

Methods: The expression of ASNS was evaluated in HCC samples by real-time PCR and immunohistochemistry assays. The correlation between ASNS expression and clinicopathological features was investigated. Potential clinicopathological prognostic factors were examined by univariate and multivariate survival analysis. Asparagine synthetase was overexpressed and knocked down in HCC cell lines to assess the influence of the enzyme on cell proliferation, migration and tumourigenicity. L-asparaginase was used to treat HCC cells with high or low levels of ASNS in vitro and in vivo to examine the therapeutic efficacy.

Results: The expression of ASNS was higher in HCC tumour tissues and was closely correlated with the serum AFP level, tumour size, microscopic vascular invasion, tumour encapsulation, TNM stage and BCLC stage. Patients with low ASNS expression levels had a poor prognosis with respect to overall survival (OS). The multivariate survival analysis indicated that ASNS is an independent prognostic factor for OS. Furthermore, functional studies demonstrated that ASNS significantly inhibits the proliferation, migration and tumourigenicity of HCC cells. The knockdown of ASNS markedly increased sensitivity to L-asparaginase, indicating that cells with different ASNS protein levels have different sensitivities to L-asparaginase.

Conclusion: The expression of ASNS is an independent factor affecting the survival of HCC patients, and low ASNS expression in HCC was correlated with worse surgical outcomes. The ASNS may be a promising therapeutic target for the treatment of HCC.

Hepatocellular carcinoma (HCC) is one of the most common malignant neoplasms and is the third leading cause of death from cancer worldwide (Ferlay et al, 2010; El-Serag, 2011). Despite the many types of treatments available, such as surgical resection, local ablation, transplantation and transcatheter arterial chemoembolisation (TACE), the prognosis remains dismal. Across all countries,

\footnotetext{
*Correspondence: Professor J-H Yang; E-mail: ehbhjhyang@163.com or Professor H-Y Wang; E-mail: hywangk@vip.sina.com ${ }^{4}$ These authors contributed equally to this work.
} 
the 5-year overall survival (OS) rate for HCC is only 3-5\% (Shariff et al, 2009; Ferlay et al, 2010). The poor prognosis of patients with HCC is largely because of the high frequencies of recurrence and metastasis after surgical resection, in addition to resistance to systemic chemotherapy (El-Serag, 2011). The limited therapeutic options and poor prognosis have triggered a search for molecular markers related to clinical outcomes, and newly identified markers will provide possible targets for preventing the progression of HCC.

The asparagine synthetase (ASNS) gene encodes the enzyme that catalyses the biosynthesis of asparagine from aspartate; this reaction proceeds in an ATP-dependent manner with glutamine serving as the nitrogen source (Richards and Schuster, 1998). The transcription of the ASNS gene is highly regulated by the nutritional status of the cell (Kilberg and Barbosa-Tessmann, 2002). Early studies demonstrated that the elevated expression of ASNS is correlated with the resistance of leukaemic cells to L-asparaginase, which is a universally used component of treatments for childhood acute lymphoblastic leukaemia (ALL) and some forms of acute myeloblastic leukaemia (AML) (Prager and Bachynsky, 1968; Hutson et al, 1997; Amylon et al, 1999; Aslanian et al, 2001; Pui et al, 2002; Zwaan et al, 2002). Similarly, ASNS is considered as a causal, predictive biomarker for L-asparaginase activity in ovarian cancer cells (Lorenzi et al, 2006, 2008). Furthermore, it has also been shown that the enhanced expression of ASNS protects pancreatic cancer cells from apoptosis induced by glucose deprivation and cisplatin (Cui et al, 2007). The results of recent studies suggest that ASNS is upregulated in castration-resistant prostate cancer (CRPC) and that the depletion of asparagine using ASNS inhibitors might be a novel strategy for targeting CRPC cells (Sircar et al, 2012). However, the expression and the functional roles of ASNS in solid tumours remain uncertain, especially in HCC. The significance of the ASNS expression level in the prognosis of HCC patients who undergo hepatectomy has not been reported. Using a proteomics approach, we identified elevated ASNS expression in HCC tumour tissues compared with normal liver specimens. Therefore, it is meaningful to investigate the clinical significance and biological function of ASNS in the development of HCC.

This study aimed to investigate the ASNS expression pattern and determine its contribution with HCC progression and its clinical prognostic value. In addition, the functional role of ASNS in HCC development and its therapeutic potential were also addressed. The results indicate that the expression of ASNS is significantly correlated with clinical characteristics and is able to predict HCC patients' outcomes after surgical resection. This enzyme may also serve as a chemotherapy target for the treatment of HCC.

\section{MATERIALS AND METHODS}

Patients and follow-up. A total of 269 adult patients with HCC undergoing hepatectomy by three independent surgical teams at the Eastern Hepatobiliary Surgery Hospital from 1 July 2002 to 30 June 2007 were enrolled in the study. The histological grade of the tumour was defined according to the Edmondson grading system. Tumour staging was performed according to the sixth edition of the tumour-node-metastasis (TNM) classification of the International Union Against Cancer and the Barcelona Clinic Liver Cancer (BCLC) staging systems. The specific material included in this study was selected to include patients who underwent surgery without chemotherapy or radiotherapy at a time when these adjunctive therapies were not the standard of treatment. Paraffinembedded tumour tissues were available for the patients included in this study. The follow-up period was defined as the interval from the date of surgery to the date of death or the last follow-up. Patients who died from other causes were treated as censored cases. All patients were observed until July 2012. Overall survival was defined as the interval between the dates of surgery and death. Disease-free survival (DFS) was defined as the interval between the dates of surgery and recurrence; if recurrence was not diagnosed, patients were censored at the date of death or the last follow-up. A total of 58 pairs of HCC specimens were selected as the test set for PCR and western blot assays. Eighteen normal liver tissues were collected from patients with hemangiomas as normal controls at the Eastern Hepatobiliary Surgery Hospital. Patient samples were obtained following the provision of written informed consent according to an established protocol approved by the Ethics Committee of the Eastern Hepatobiliary Surgery Hospital. The investigations were conducted according to the principles of the Declaration of Helsinki.

Tissue microarray and immunohistochemistry analysis. After screening haematoxylin and eosin (H\&E)-stained slides for optimal tumour content, we constructed tissue microarray (TMA) slides (Shanghai Biochip Company, Ltd., Shanghai, China). Two punch cores measuring $0.8 \mathrm{~mm}$ in the greatest dimension from the centre of the tumour focus were taken from each formalin-fixed, paraffinembedded HCC sample and normal liver sample. Immunohistochemistry was performed as described previously (Dong et al, 2011). The sections were incubated with a primary polyclonal antibody against ASNS (P08243; Abbiotec, San Diego, CA, USA) in a 1:500 dilution. Finally, the visualisation signal was developed with diaminobenzidine, and the slides were counterstained with haematoxylin. Stained sections were evaluated in a blinded manner without prior knowledge of the clinical information using the German immunoreactivity score (IRS) as described previously (Wang et al, 2011). Briefly, the IRS assigns subscores for the distribution (0-4) and intensity (0-3) of the immunoreactivity and then multiplies them to yield the IRS. The percent positivity was scored as ' 0 ' (<5\%), ' 1 ' (5-25\%), ' 2 ' (25-50\%), ' 3 ' (50-75\%) or ' 4 ' ( $>75 \%)$. The staining intensity was scored as ' 0 ' (no staining), ' 1 ' (weakly stained), '2' (moderately stained) or ' 3 ' (strongly stained). Cases with discrepancies in the IRSs were discussed together with other pathologists until a consensus was reached.

Xenograft tumour model and in vivo metastasis assay. Six-weekold nude mice were purchased from the Shanghai Experimental Center (CSA, Shanghai, China). All animal experiments met the requirements of the Second Military Medical University Animal Care Facility and the National Institutes of Health guidelines. A total of $5 \times 10^{6}$ cells suspended in $100 \mu$ l of Hanks' buffered saline solution were injected subcutaneously into the lower flanks of nude mice. The tumour volumes were measured using callipers every week and calculated using the formula: volume $=$ length $\times$ width $^{2} \times 0.5$. For the metastasis assay, 22 nude mice were randomised into two groups. A total of $2 \times 10^{6}$ cells were injected into the tail vein of nude mice. Four mice in each group were killed 4 weeks after inoculation, and consecutive sections of the whole lung were subjected to H\&E staining. All of the metastatic foci in the lungs were assessed microscopically to evaluate the development of pulmonary metastasis. The remaining mice were monitored for survival analysis.

Statistical analysis. Pearson's $\chi^{2}$ test or Fisher's exact test was used to analyse the relationship between ASNS expression and the clinicopathologic features. Survival curves were calculated using the Kaplan-Meier method and compared using the log-rank test. The Cox proportional-hazard regression model was used for analyses to explore the effect of the clinicopathological variables and ASNS expression on survival. SPSS 17.0 software (SPSS Inc., Chicago, IL, USA) was used for all statistical analyses, and $P$-values of $<0.05$ were considered statistically significant. Additional 
information on Materials and Methods can be found in Supplementary Information.

\section{RESULTS}

ASNS is overexpressed in HCC tumour specimens. Using a proteomics approach, we found that the ASNS protein level was much higher in HCC tumour tissues than in normal liver specimens (data not shown). A real-time RT-PCR assay was performed to analyse ASNS transcripts in frozen paired samples derived from 58 patients with HCC and 18 normal liver tissues. The level of ASNS mRNA varied greatly between the tumour and adjacent tissues, with $76 \%$ (44 of 58) of tumour tissues having higher expression than the normal tissues (Figure 1A and B). The upregulation of ASNS was confirmed by immunoblotting and immunohistochemical assays (Figure $1 \mathrm{C}$ and $\mathrm{E}$ ). The protein and
mRNA levels of ASNS in HCC cell lines were also determined (Figure 1D).

The ASNS protein in the liver tissues of DEN carcinogenesis rats was stained immunohistochemically to observe the dynamic expression of ASNS during the progression from hepatitis to cirrhosis to HCC. As shown in Figure 1F, the level of ASNS expression was significantly higher in the livers of the DEN-treated rats than in the livers of the control group after DEN had been injected for 8 weeks. The highest expression was observed at 12-14 weeks, a period that corresponds to advanced cirrhosis and early HCC. The ASNS expression level was moderately decreased between weeks 16 and 20, which represents the advanced HCC stage (Figure 1F). In accordance with the findings in the animal model experiments, in the clinical samples, high ASNS expression was associated with a smaller tumour size and an earlier tumour stage, and low ASNS expression correlated with a larger tumour size and a more advanced tumour stage (Figure 1G and Table 1).
A

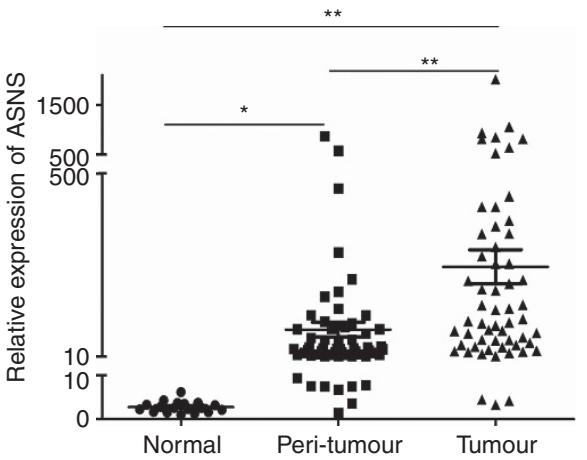

B

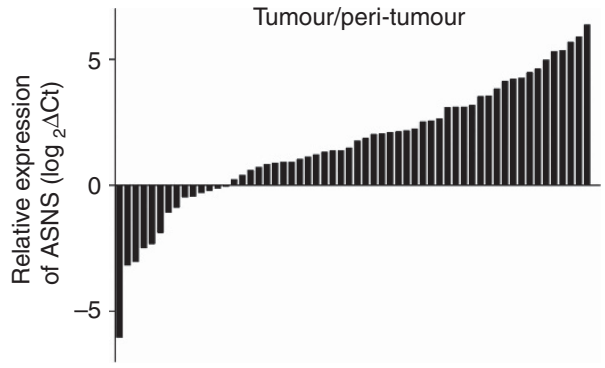

C

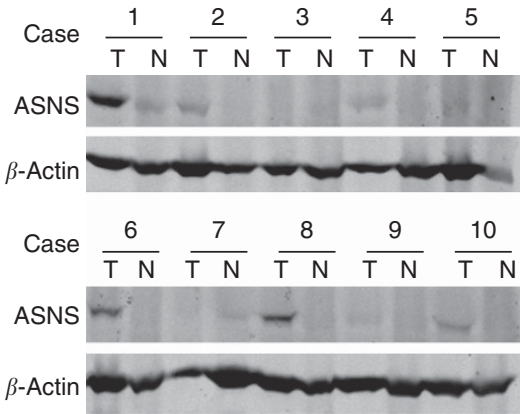

D

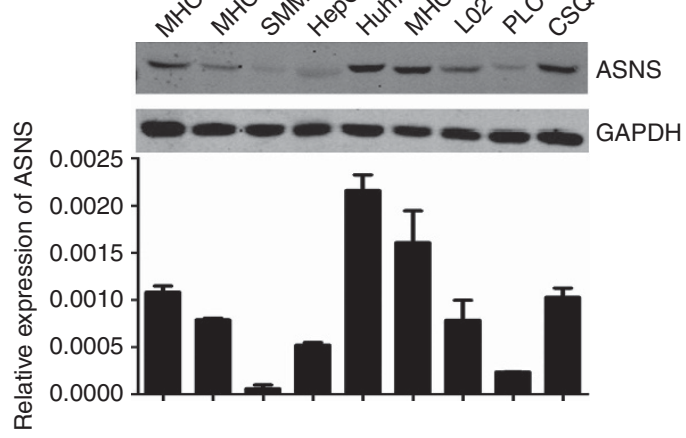

E

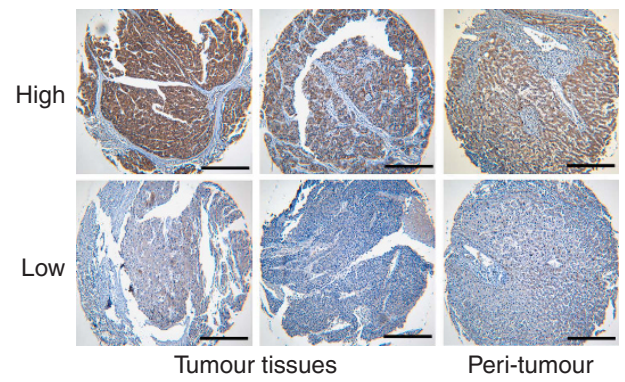

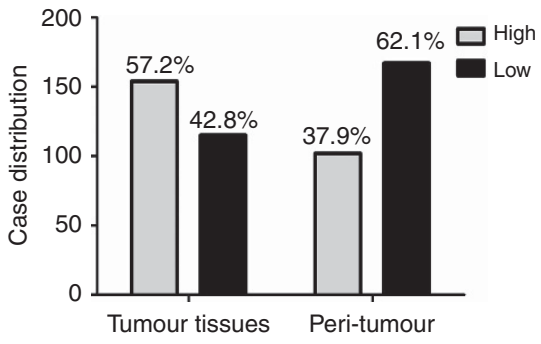

Figure 1. Expression of ASNS is upregulated in HCC. (A) The ASNS mRNA levels in HCC and normal liver tissues were detected by real-time PCR. (B) Relative ASNS mRNA expression levels in paired HCC samples $(n=58)$. (C) Representative western blot showing the expression of the ASNS protein in tumour tissue $(T)$ and paired peri-tumour tissue $(\mathrm{N})$ from HCC patients. (D) The expression of ASNS in HCC cell lines was examined by western blotting and a real-time PCR assay. (E) The TMA assay detection of ASNS expression. The TMA was stained with an anti-ASNS antibody, and the samples were grouped into high and low expression group according to the ASNS intensity (magnification, $\times 100$ ). The scale bars correspond to $0.2 \mathrm{~mm}$. (F) The ASNS protein was stained in liver tissues from DEN carcinogenesis rats by immunohistochemistry (magnification, $\times 100$ ). The scale bars correspond to $0.3 \mathrm{~mm}$. (G) The case distributions of high and low ASNS levels among the $269 \mathrm{HCC}$ patients were compared for different tumour sizes and TNM stages. ${ }^{\star} P<0.05,{ }^{* \star} P<0.01$. 


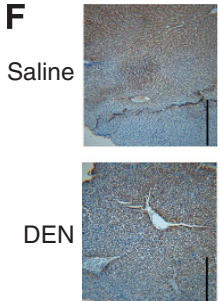

$6 \mathrm{~W}$
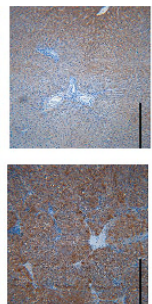

$8 \mathrm{~W}$
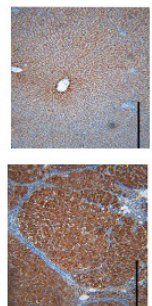

$10 \mathrm{~W}$
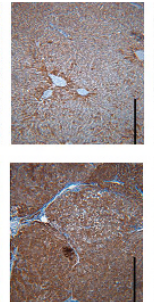

$12 \mathrm{~W}$

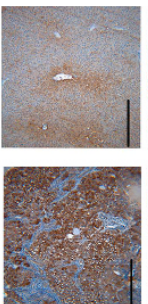

$14 \mathrm{~W}$

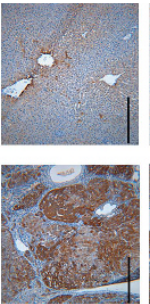

$16 \mathrm{~W}$

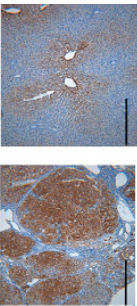

$18 \mathrm{~W}$

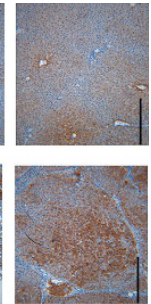

$20 \mathrm{~W}$

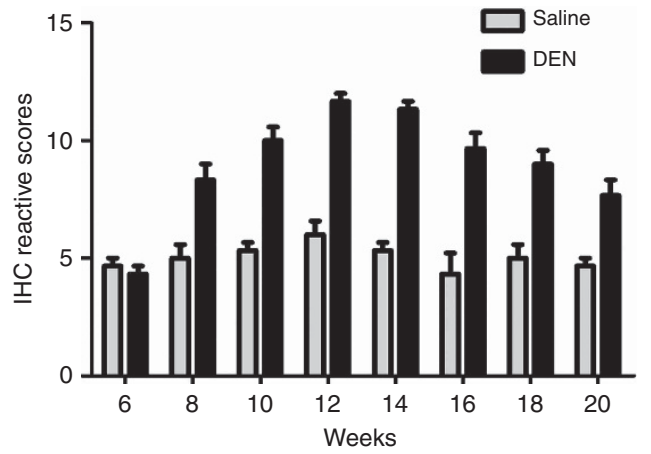

G

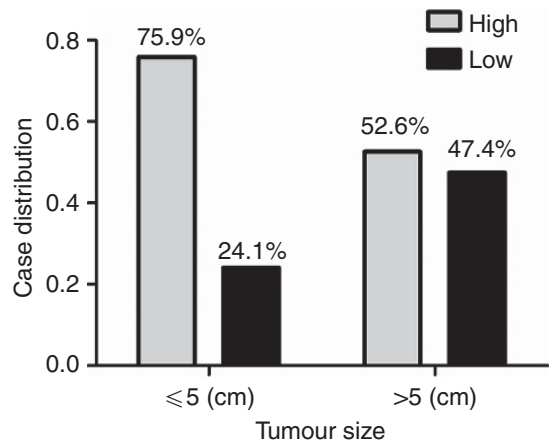

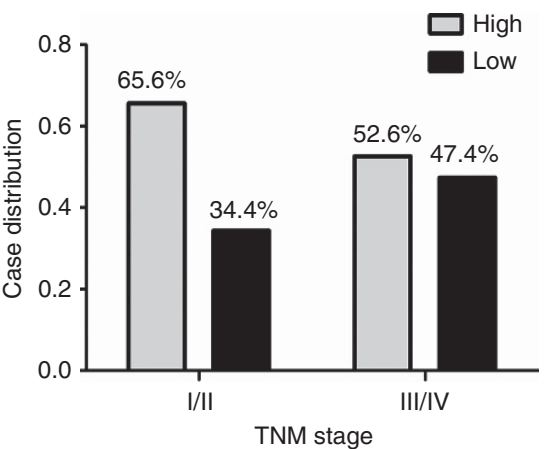

Figure 1. Continued.

Association of ASNS expression with clinicopathological features. We next examined the relationship between the ASNS expression levels in tumour tissues and the clinicopathological characteristics of 269 patients using TMA analysis (Table 1). Pearson's $\chi^{2}$ test indicated that the expression of ASNS was significantly correlated with the serum AFP level $(P=0.040)$, tumour size $(P=0.002)$, microscopic vascular invasion $(P=0.003)$, tumour encapsulation $(P=0.007)$, TNM stage $(P=0.039)$ and BCLC stage $(P=0.039)$. The same result was also observed in an additional cohort containing 133 patients (Supplementary Table 1). Other clinical characteristics were not closely correlated with the expression of ASNS, including age, gender, tumour number, intrahepatic metastasis, distant metastasis, portal venous invasion, cirrhosis and history of hepatitis.

Association of the ASNS expression level with prognosis. The Kaplan-Meier survival curves comparing patients with high ASNS expression with patients with low expression in a group of 269 HCC patients are shown in Figure 2. The ASNS expression level was negatively correlated with the 1-, 3- and 5-year survival rates (52.6\%, $29.2 \%$ and $25.3 \%$ for high ASNS expression vs $37.4 \%$, $20.0 \%$ and $13.9 \%$ for low expression, respectively; $P=0.002,0.005$ and 0.002 ). In addition, the 1-, 3- and 5-year DFS rates for the patients with high ASNS expression were lower than those for the patients with low ASNS expression; however, the difference was not significant.

The univariate analysis of recurrence-related and survivalrelated clinicopathological variables revealed that the ASNS and serum AFP levels were predictors of OS. Gender, HBV infection, tumour size, intrahepatic metastasis, portal venous invasion, distant metastasis, microscopic vascular invasion, encapsulation, TNM stage and BCLC stage were statistically correlated with both recurrence and survival. These individual parameters were further subjected to multivariate Cox proportional-hazards model, which demonstrated that the ASNS expression level, together with HBV infection, intrahepatic metastasis, microscopic vascular invasion and the BCLC stage, was strongly associated with OS (Table 2). Asparagine synthetase was an independent prognostic indicator for the survival of HCC patients (HR $0.744,95 \%$ CI $0.565-0.979$, $P=0.035)$.

ASNS knockdown promotes the proliferation and tumourigenicity of HCC cell lines. We infected HCC cells with a lentivirus to deliver shRNA targeting ASNS and constructed stably transfected MHCCLM3 and MHCC97H cells. In addition, SMMC7721 cells were transiently transfected with the GV142/ASNS vector. The expression of ASNS was verified by immunoblotting (Figure 3A). We found that the overexpression of ASNS in SMMC7721 cells suppressed cell proliferation in a CCK-8 assay (Figure 3B). Furthermore, ASNS knockdown resulted in increased proliferation and colony formation for both MHCCLM3 and MHCC97H cells compared with control cells (Figure 3B and D). The analysis of the cell cycle distribution demonstrated that ASNS knockdown could hasten cell cycle progression (Figure $3 \mathrm{C}$ ). In addition, we found that the cyclin D1 protein level decreased in ASNS-overexpressing cells but increased in ASNS-knockdown cells (Figure 3A). Stably 


\begin{tabular}{|c|c|c|c|c|}
\hline & & ASNS ex & $\mathrm{n}$ in $\mathrm{HC}$ & \\
\hline Characteristics & No. of patients & Low & High & $P$-value \\
\hline Age (years) & & & & 0.409 \\
\hline $\begin{array}{l}\leqslant 50 \\
\leqslant 50\end{array}$ & $\begin{array}{l}156 \\
113\end{array}$ & $\begin{array}{l}70 \\
45\end{array}$ & $\begin{array}{l}86 \\
68\end{array}$ & \\
\hline Gender & & & & 0.477 \\
\hline $\begin{array}{l}\text { Male } \\
\text { Female }\end{array}$ & $\begin{array}{r}236 \\
33\end{array}$ & $\begin{array}{l}99 \\
16\end{array}$ & $\begin{array}{r}137 \\
17\end{array}$ & \\
\hline HBV & & & & 0.972 \\
\hline $\begin{array}{l}\text { Negative } \\
\text { Positive }\end{array}$ & $\begin{array}{r}40 \\
229\end{array}$ & $\begin{array}{l}17 \\
98\end{array}$ & $\begin{array}{r}23 \\
131\end{array}$ & \\
\hline Serum AFP & & & & 0.040 \\
\hline $\begin{array}{l}\left.\leqslant 400 \mathrm{ml}^{-1}\right) \\
\leqslant 400 \mathrm{ngl}^{-1} \text { ) }\end{array}$ & $\begin{array}{r}81 \\
188\end{array}$ & $\begin{array}{l}27 \\
88\end{array}$ & $\begin{array}{r}54 \\
100\end{array}$ & \\
\hline Largest tumour size & & & & 0.002 \\
\hline $\begin{array}{l}\leqslant 5(\mathrm{~cm}) \\
\leqslant 5(\mathrm{~cm})\end{array}$ & $\begin{array}{r}54 \\
215\end{array}$ & $\begin{array}{r}13 \\
102\end{array}$ & $\begin{array}{r}41 \\
113\end{array}$ & \\
\hline Tumour number & & & & 0.789 \\
\hline $\begin{array}{l}\text { Single } \\
\text { Multiple }\end{array}$ & $\begin{array}{r}247 \\
22\end{array}$ & $\begin{array}{r}105 \\
10\end{array}$ & $\begin{array}{r}142 \\
12\end{array}$ & \\
\hline Intrahepatic metastasis & & & & 0.619 \\
\hline $\begin{array}{l}\text { Negative } \\
\text { Positive }\end{array}$ & $\begin{array}{l}145 \\
124\end{array}$ & $\begin{array}{l}64 \\
51\end{array}$ & $\begin{array}{l}81 \\
73\end{array}$ & \\
\hline Distant metastasis & & & & 0.365 \\
\hline $\begin{array}{l}\text { Negative } \\
\text { Positive }\end{array}$ & $\begin{array}{r}188 \\
81\end{array}$ & $\begin{array}{l}77 \\
38\end{array}$ & $\begin{array}{r}111 \\
43\end{array}$ & \\
\hline Portal venous invasion & & & & 0.222 \\
\hline $\begin{array}{l}\text { Negative } \\
\text { Positive }\end{array}$ & $\begin{array}{l}113 \\
156\end{array}$ & $\begin{array}{l}43 \\
72\end{array}$ & $\begin{array}{l}69 \\
85\end{array}$ & \\
\hline Microscopic vascular invasion & & & & 0.003 \\
\hline $\begin{array}{l}\text { Negative } \\
\text { Positive }\end{array}$ & $\begin{array}{r}29 \\
240\end{array}$ & $\begin{array}{r}5 \\
110\end{array}$ & $\begin{array}{r}24 \\
130\end{array}$ & \\
\hline Cirrhosis & & & & 0.692 \\
\hline $\begin{array}{l}\text { Negative } \\
\text { Positive }\end{array}$ & $\begin{array}{r}83 \\
186\end{array}$ & $\begin{array}{l}34 \\
81\end{array}$ & $\begin{array}{r}49 \\
105\end{array}$ & \\
\hline Tumour encapsulation & & & & 0.007 \\
\hline $\begin{array}{l}\text { No } \\
\text { Yes }\end{array}$ & $\begin{array}{r}172 \\
97\end{array}$ & $\begin{array}{l}84 \\
31\end{array}$ & $\begin{array}{l}88 \\
66\end{array}$ & \\
\hline BCLC stage & & & & 0.039 \\
\hline $\begin{array}{l}\text { A } \\
B \\
C\end{array}$ & $\begin{array}{r}11 \\
92 \\
166\end{array}$ & $\begin{array}{r}2 \\
33 \\
80\end{array}$ & $\begin{array}{r}9 \\
59 \\
86\end{array}$ & \\
\hline TNM & & & & 0.039 \\
\hline $\begin{array}{l}\text { I/II } \\
\text { III/IV }\end{array}$ & $\begin{array}{r}96 \\
173\end{array}$ & $\begin{array}{l}33 \\
82\end{array}$ & $\begin{array}{l}63 \\
91\end{array}$ & \\
\hline \multicolumn{5}{|c|}{$\begin{array}{l}\text { Abbreviations: } \mathrm{AFP}=\alpha \text {-fetoprotein; } \mathrm{ASNS}=\text { asparagine synthetase; } \mathrm{BCLC}=\text { Barcelona } \\
\text { Clinic Liver Cancer; } \mathrm{HBV}=\text { hepatitis } \mathrm{B} \text { virus; } \mathrm{HCC}=\text { hepatocellular carcinoma; } \mathrm{TNM}= \\
\text { tumour-node-metastasis. All the significant values are indicated in bold. }\end{array}$} \\
\hline
\end{tabular}

transfected MHCCLM3 cells were inoculated into the flanks of nude mice, and the effect of ASNS on xenograft tumour growth was observed. Compared with control cells, ASNS-knockdown cells resulted in significantly larger tumours (Figure 3E). These results indicate that ASNS knockdown promotes HCC growth both in vitro and in vivo.

ASNS knockdown enhances the metastatic potential of HCC cells. To investigate the effects of ASNS knockdown on the behaviour of HCC cells, transwell experiments were performed. The results indicate that the depletion of ASNS markedly increased cell migration and the invasion capacity. The restoration of ASNS expression in SMMC7721 cells suppressed cell migration (Figure 4A). To further examine the effect of ASNS knockdown, stably transfected MHCC97H cells were injected into the tail veins of nude mice. After 6 weeks, ASNS knockdown resulted in a significantly increased number and size of pulmonary metastatic lesions (Figure 4B). Furthermore, the ASNS knockdown group had a shorter survival period than the control group (Figure 4C). These results demonstrate that HCC cells with low ASNS expression levels have an enhanced metastatic potential.

ASNS knockdown increases sensitivity to L-asparaginase in vitro and vivo. To determine whether ASNS expression is correlated with the sensitivity to L-asparaginase, a drug that is a standard component of the chemotherapy regimens for leukaemia, HCC cells were treated with L-asparaginase, and cell proliferation was assessed using the CCK-8 assay. Compared with cells with high ASNS expression (MHCCLM3 and MHCC97H), cells with low ASNS expression (SMMC7721 and PLC) were much more sensitive to L-asparaginase (Figure 5A). Moreover, the analysis of the stably transfected HCC cells revealed the decreased proliferation of ASNS-knockdown cells in the presence of L-asparaginase compared with control cells (Figure 5B). Furthermore, the effect of $\mathrm{L}$-asparaginase was also observed in vivo. Nude mice bearing MHCCLM3 tumour xenografts were treated with L-asparaginase every other day by intraperitoneal injection. As shown in Figure 5C, the ASNS-knockdown group exhibited delayed tumour formation and a significant reduction in tumour size compared with the control group. These results indicate that cells with low ASNS expression are more sensitive to L-asparaginase.

\section{DISCUSSION}

In this study, we demonstrated the upregulation of ASNS at both the mRNA and protein levels in HCC. The association of ASNS expression with clinicopathological features was further investigated in HCC patients using TMA. This analysis revealed significant correlations between ASNS expression and many clinical features, indicating that low ASNS expression is associated with malignant clinicopathological characteristics. In the DEN carcinogenesis rat model, ASNS was highly expressed from the inflammation stage to the advanced HCC stage, reaching a peak during the advanced cirrhosis and early HCC stage. Moreover, moderately decreased ASNS expression was observed in advanced cancer in comparison with early cancer in human HCC clinical specimens. The Kaplan-Meier analysis showed that patients with HCC who had high ASNS expression in general had a better prognosis than those with low ASNS expression. Multivariate analysis revealed that the ASNS expression level might be an independent and significant prognostic indicator affecting survival after surgical resection. To the best of our knowledge, this is the first time that ASNS has been proposed as a prognostic marker for HCC, and our results suggest that ASNS expression in HCC is an ideal biomarker that has strong associations with disease outcomes. The low expression of ASNS identified by postoperative immunostaining might be an early warning sign that patients should be closely monitored and receive appropriate adjuvant therapies.

Confirming the role of ASNS in HCC, low-ASNS cells showed increased proliferation and colony formation ability in vitro and elevated tumourigenicity in xenografts in nude mice. In accordance with the correlation analysis, these results indicate that ASNS is a tumour growth suppressor in HCC. Because of the catalysing function of this enzyme, ASNS knockdown may lead to the accumulation of aspartate and glutamine, which are essential components in the biosynthesis of purines and pyrimidines. We hypothesised that the intracellular metabolism shifted to nucleic acid synthesis, which affected proliferation. Previous studies, however, have demonstrated that ASNS is necessary for G1 progression in hamster BHK ts11 cells and that the loss of ASNS activity can lead to cell cycle arrest (Greco et al, 1987; Gong and 

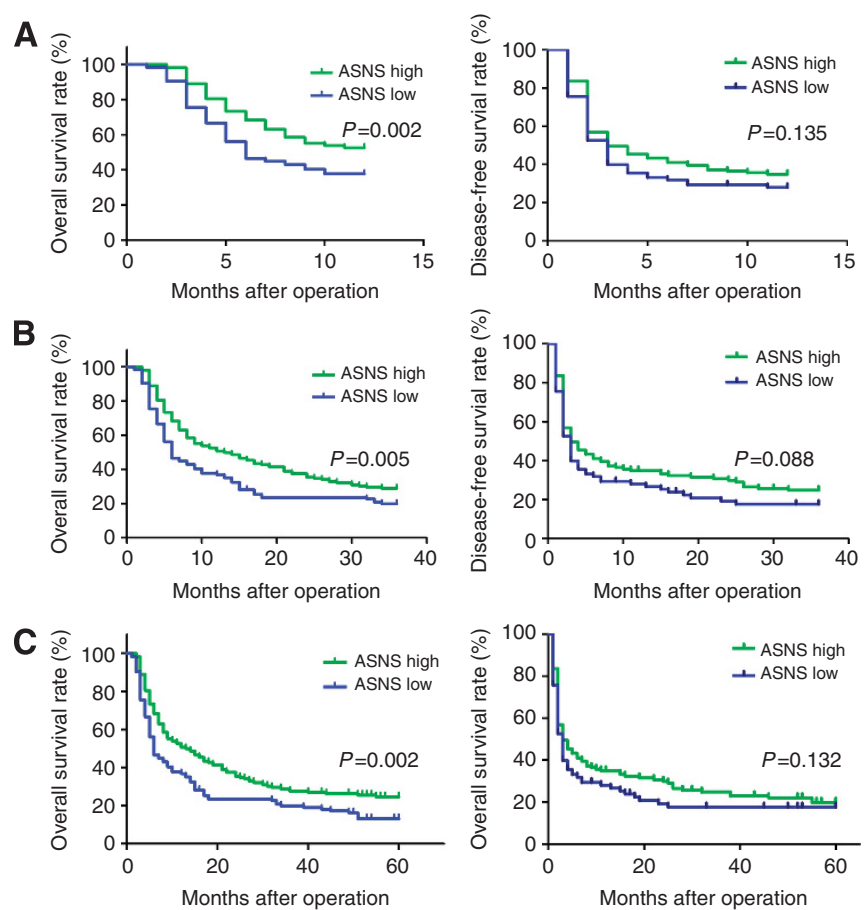

Figure 2. Kaplan-Meier curves for time to recurrence and the overall survival of patients with high and low intratumoural ASNS levels. (A-C) The 1-, 3- and 5-year overall survival rates and the disease-free survival rates were analysed in the low and high ASNS groups in the TMA training set. The different subgroups were plotted according to the scores for the ASNS levels.
Basilico, 1990). The conflicting evidence indicates that the roles of ASNS might vary in different tissues or organs, and these differences should be investigated further. Clinicopathological association studies suggest that ASNS can inhibit microscopic vascular invasion. The overexpression of ASNS severely inhibited the migration capacity of cells and ASNS knockdown significantly increased the migration and invasion abilities of cells in vitro. These results were confirmed by the in vivo pulmonary metastasis model. To the best of our knowledge, this is the first that it has been reported that ASNS expression is critical for HCC metastasis in addition to tumour growth.

Our studies indicated that the upregulated expression of ASNS was moderately decreased from the early stage to the advanced stage of HCC. The expression pattern of this protein in the rat model was consistent with that in human HCC clinical sample and with the results of studies of the functional role of ASNS in cells. In later investigations, we also observed that ASNS overexpression increased the sensitivity of cells to apoptosis when exposed to various stimuli (data not shown). Based on these results, we hypothesised that starting from the inflammation stage, the high expression of ASNS is associated with damage to hepatocytes, which leads to compensatory hyperplasia. During the advanced cirrhosis and early HCC stage, ASNS expression reaches a peak, and tumours develop because of hepatocyte damage and the dysregulation of compensatory hyperplasia.

L-asparaginase, an enzyme that catalyses the hydrolysis of asparagine to aspartic acid, has been employed in the treatment of ALL for almost 50 years (Haskell, 1981; Verma et al, 2007). In addition, natural killer cell tumours and subtypes of myeloid leukaemia and T-cell lymphomas respond to L-asparaginase (Tezuka et al, 2002; Okada et al, 2003; Ando et al, 2005;

Table 2. Univariate and multivariate Cox regression analyses of ASNS for DFS or OS of patients $(n=269)$

\begin{tabular}{|c|c|c|c|c|}
\hline \multirow[b]{2}{*}{ Variables } & \multicolumn{2}{|l|}{ DFS } & \multicolumn{2}{|l|}{ OS } \\
\hline & Hazard ratio $(95 \% \mathrm{Cl})^{a}$ & $\boldsymbol{P}$-value & $\begin{array}{l}\text { Hazard ratio }(95 \% \\
\qquad \mathrm{Cl})^{\mathrm{a}}\end{array}$ & $\boldsymbol{P}$-value \\
\hline \multicolumn{5}{|l|}{ Univariate analysis } \\
\hline $\begin{array}{l}\text { ASNS (high vs low) } \\
\text { Age ( }>50 \text { vs } \leqslant 50 \text { years) } \\
\text { Gender (male vs female) } \\
\text { HBV ( negative vs positive) } \\
\text { Serum AFP ( }>400 \text { vs } \leqslant 400 \mathrm{ng} \mathrm{ml}^{-1} \text { ) } \\
\left.\text { Largest tumour size ( }>5 \text { vs } \leqslant 5 \mathrm{~cm}^{2}\right) \\
\text { Intrahepatic metastasis (negative vs positive) } \\
\text { Portal venous invasion (negative vs positive) } \\
\text { Distant metastasis (negative vs positive) } \\
\text { Microscopic vascular invasion (negative vs positive) } \\
\text { Encapsulation } \\
\text { Cirrhosis (negative vs positive) } \\
\text { TNM stage (I }+\| \text { vs III }+\mathrm{IV}) \\
\text { BCLC stage (A vs B }+\mathrm{C})\end{array}$ & $\begin{array}{l}0.823(0.619-1.092) \\
0.910(0.687-1.206) \\
0.585((0.360-0.950) \\
1.904(1.006-3.603) \\
1.305(0.960-1.775) \\
2.570(1.713-3.856) \\
1.419(1.068-1.887) \\
1.798(1.339-2.412) \\
2.028(1.520-2.707) \\
3.719(2.014-6.868) \\
0.554(0.408-0.753) \\
1.198(0.886-1.621) \\
2.041(1.498-2.781) \\
1.975(1.512-2.579)\end{array}$ & $\begin{array}{l}0.177 \\
0.513 \\
0.030 \\
0.048 \\
0.090 \\
<0.001 \\
0.016 \\
<0.001 \\
<0.001 \\
<0.001 \\
<0.001 \\
0.241 \\
<0.001 \\
<0.001\end{array}$ & $\begin{array}{l}0.659(0.503-0.863) \\
0.793(0.604-1.042) \\
0.568(0.358-0.901) \\
1.515(1.023-2.224) \\
1.380(1.023-1.861) \\
2.378(1.613-3.508) \\
1.870(1.427-2.451) \\
2.448(1.835-3.265) \\
1.391(1.046-1.850) \\
4.117(2.239-7.570) \\
0.501(0.372-0.676) \\
1.320(0.979-1.779) \\
2.617(1.928-3.553) \\
2.657(2.018-3.498)\end{array}$ & $\begin{array}{l}0.002 \\
0.095 \\
0.016 \\
0.038 \\
0.034 \\
<0.001 \\
<0.001 \\
<0.001 \\
0.023 \\
<0.001 \\
<0.001 \\
0.068 \\
<0.001 \\
<0.001\end{array}$ \\
\hline \multicolumn{5}{|l|}{ Multivariate analysis } \\
\hline $\begin{array}{l}\text { ASNS (high vs low) } \\
\text { HBV ( negative vs positive) } \\
\text { Serum AFP ( }>400 \text { vs } \leqslant 400 \mathrm{ng} \mathrm{m}^{-1} \text { ) } \\
\text { Largest tumour size }(>5 \text { vs } \leqslant 5 \mathrm{~cm} \text { ) } \\
\text { Intrahepatic metastasis (negative vs positive) } \\
\text { Portal venous invasion (negative vs positive) } \\
\text { Distant metastasis (negative vs positive) } \\
\text { Microscopic vascular invasion (negative vs positive) } \\
\text { Encapsulation } \\
\text { Cirrhosis (negative vs positive) } \\
\text { TNM stage (I+II vs III }+ \text { IV) } \\
\text { BCLC stage (A vs B }+ \text { C) }\end{array}$ & $\begin{array}{c}\text { NA } \\
\text { NA } \\
\text { NA } \\
1.800(1.172-2.764) \\
\text { NA } \\
\text { NA } \\
1.694(1.264-2.270) \\
2.740(1.458-5.148) \\
\text { NA } \\
\text { NA } \\
\text { NA } \\
1.483(1.108-1.985)\end{array}$ & $\begin{array}{l}0.007 \\
\\
<0.001 \\
0.002\end{array}$ & $\begin{array}{c}0.744(0.565-0.979) \\
1.978(1.076-3.638) \\
\text { NA } \\
\text { NA } \\
1.438(1.088-1.900) \\
\text { NA } \\
\text { NA } \\
2.429(1.290-4.573) \\
\text { NA } \\
\text { NA } \\
\text { NA } \\
2.098(1.575-2.794)\end{array}$ & $\begin{array}{l}0.035 \\
0.028 \\
0.011 \\
0.006 \\
\\
<0.001\end{array}$ \\
\hline
\end{tabular}



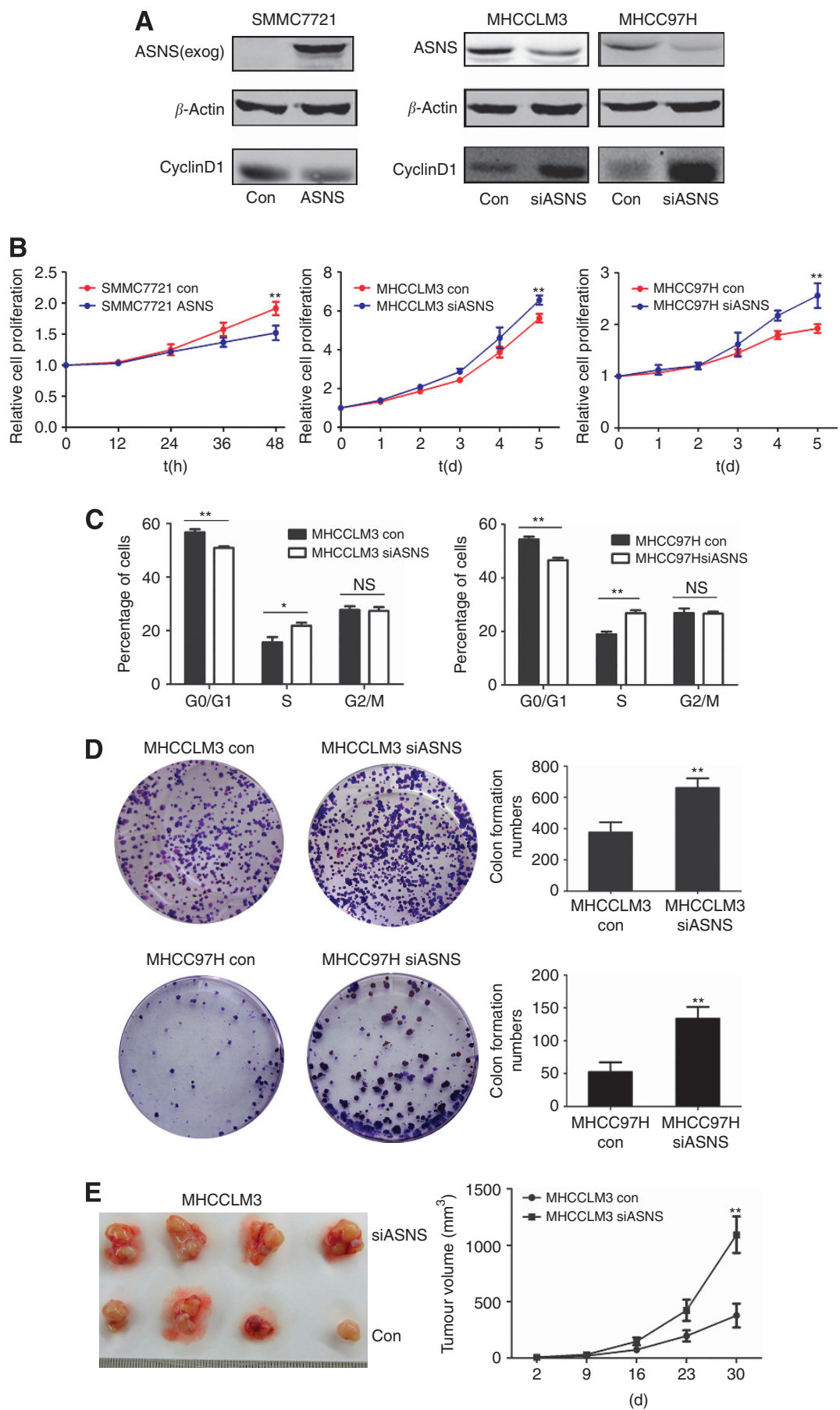

Figure 3. The expression of ASNS suppressed the proliferation of and colony formation by HCC cell lines. (A) Establishment of transient and stably transfected HCC cell lines. The SMMC7721 cells were transfected with the GV142/ASNS (ASNS) or GV142/GFP (con) plasmid. The MHCCLM3 and MHCC97H cells were infected with lentivirus/siASNS (siASNS) or lentivirus/scrambled control (Con) and evaluated by an immunoblotting assay. (B) The HCC cells $\left(2 \times 10^{3}\right.$ cells per well) were seeded in 96 -well plates and cultured overnight at $37^{\circ} \mathrm{C}$. Cell proliferation was detected using the CCK-8 assay at various time points according to the manufacturer's instructions. (C) Images of cells stained with 4,6-diamidino-2-phenylindole (DAPI) were captured using an sCMOS camera with an ImageXpress Micro XL high-content screening system (Molecular Devices, Sunnyvale, CA, USA) and were analysed using MeteXpress 4.0 software (Molecular Devices). The cell cycle distribution was calculated. (D) A panel clonogenic assay of two HCC cell lines after ASNS knockdown. The HCC cells $\left(2 \times 10^{3}\right.$ cells per well) were seeded in 6 -well plates and incubated for 10 days, and then the number of cell colonies was counted. (E) Knockdown of ASNS promoted xenograft tumour growth in nude mice. The MHCCLM3-con and MHCCLM3-siASNS cells $\left(5 \times 10^{6}\right.$ cells per mouse) were inoculated into the flanks of nude mice, and tumour growth was observed. Error bars represent the s.d. ${ }^{\star} P<0.05$, ${ }^{\star \star} P<0.01$.

Yokoyama et al, 2010). However, the exact molecular basis underlying the therapeutic utility of L-asparaginase remains ill defined (Richards and Kilberg, 2006). It was postulated years ago that leukaemic cells depend on the external availability of asparagine because of a generally low ASNS expression level. The effectiveness of L-asparaginase results in the depletion of cellular asparagine and leads to the death of leukaemic cells (Appel et al, 2006). This drug also has inherent glutaminase activity that is 

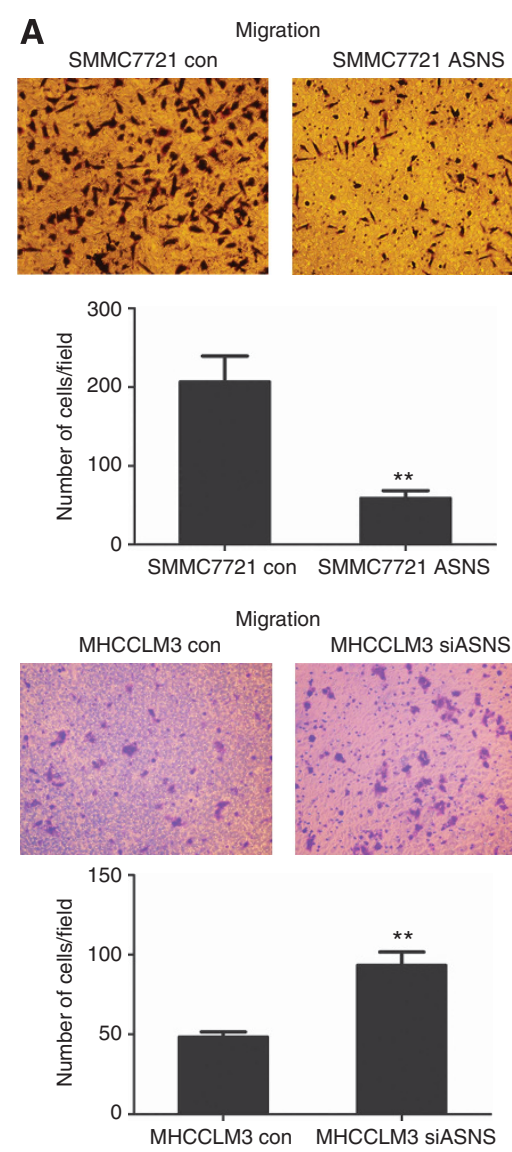

B

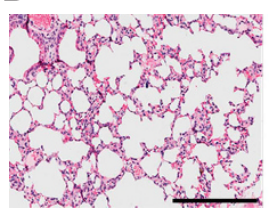

$\mathrm{MHCC} 97 \mathrm{H}$ con

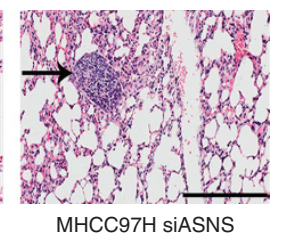

MHCC97H SIASNS

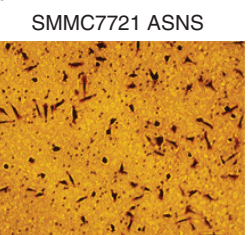

MHCCLM3 SIASNS

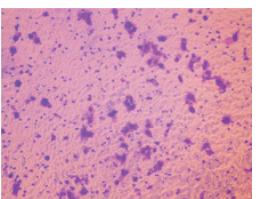

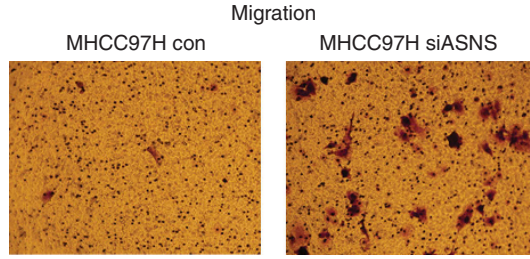

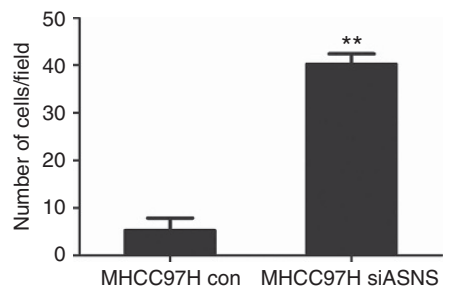

Invasion
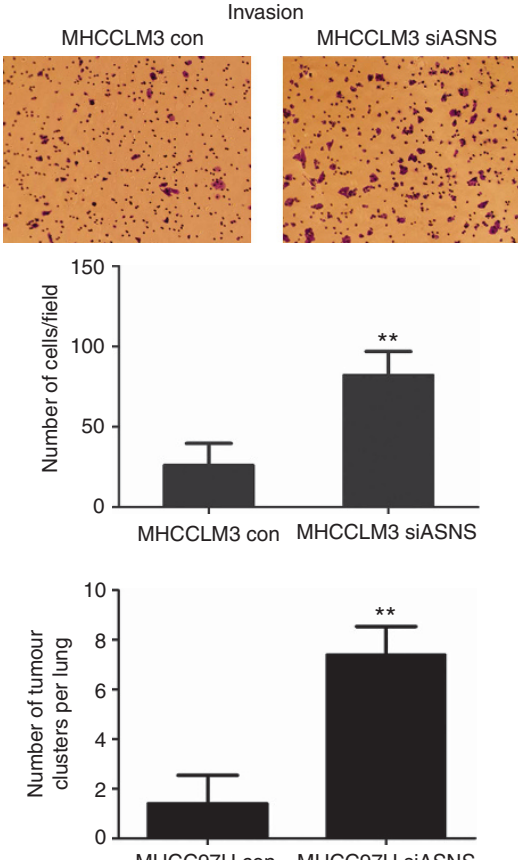

MHCC97H con MHCC97H siASNS

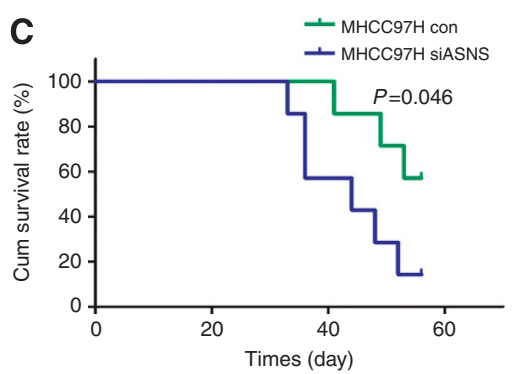

Figure 4. Knockdown of ASNS enhanced the metastatic potential of HCC cells. (A) The depletion of ASNS markedly increased the cell migration and invasion capacity of HCC cells. The SMMC7721, MHCCLM3 and MHCC97H cells $\left(2 \times 10^{5}\right.$ cells $)$ were plated into the upper chambers of polycarbonate transwell filter chambers coated with or without Matrigel and incubated for 24 or $30 \mathrm{~h}$. The cell counts are expressed as the mean number of cells per field of view (magnification, $\times 100$ ). (B and $\mathbf{C}$ ) Representative views of lung tissue sections from each group are shown (H\&E stain; magnification, $\times 100$ ). The scale bars correspond to $0.25 \mathrm{~mm}$. The number of lung metastatic foci in each group of MHCC97H siASNS or $\mathrm{MHCC} 97 \mathrm{H}$ con xenografted mice was counted using a microscope 4 weeks after tail vein injection. Black arrows indicate lung metastases (left panel). The OS of the nude mice was analysed with SPSS version 17.0. The error bars represent the s.d. ${ }^{\star *} P<0.01$.

approximately $2 \%$ to $3 \%$ of the asparaginase activity (Richards and Schuster, 1998). Glutamine is the nitrogen donor for the ASNScatalysed reaction and, as a result, the depletion of this amino acid may also play a role in the activity of asparaginase (Chen et al, 2004). Some studies have revealed that the ASNS level in ALL cells from patients might be used as a predictor of the sensitivity of the leukaemic cells to L-asparaginase (Hutson et al, 1997; Aslanian et al, 2001). However, other studies have shown that the upregulation of ASNS expression is not linked to the clinical response to L-asparaginase (den Boer et al, 2005; Appel et al, 2006; Iwamoto et al, 2007). Despite the conflicting evidence, it is generally accepted that the role of ASNS in leukaemic cells with 
A
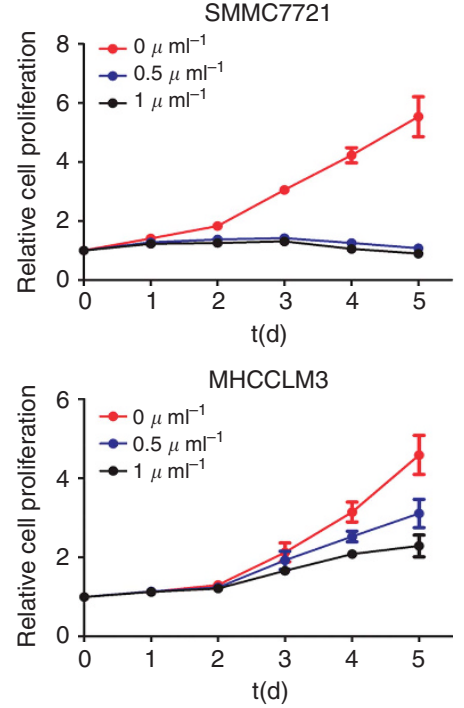

B

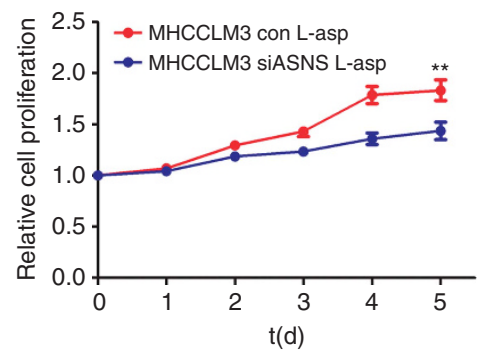

C

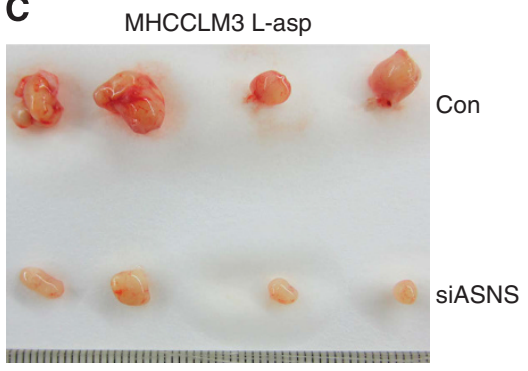

PLC
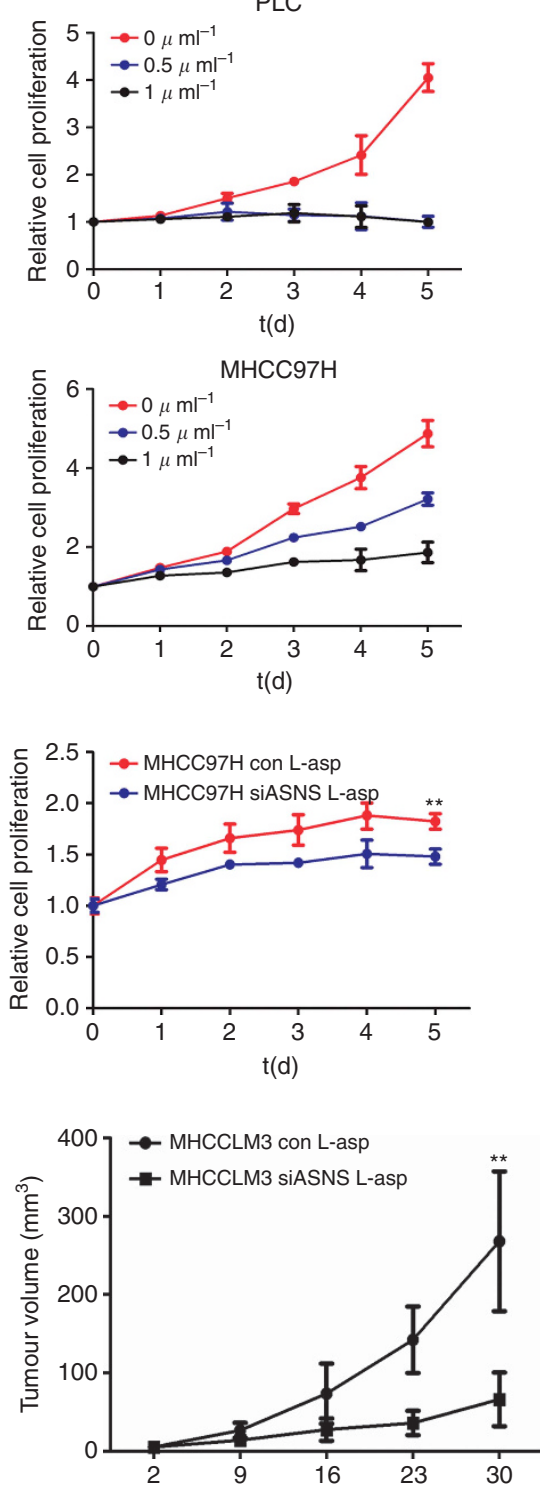

(d)

Figure 5. Knockdown of ASNS increases sensitivity to L-asparaginase. (A) The HCC cells $\left(2 \times 10^{3}\right.$ cells per well) were seeded in 96 -well plates and cultured overnight at $37^{\circ} \mathrm{C}$ with L-asparaginase (L-asp; $0,0.5$ and $1 \mu \mathrm{ml}^{-1}$ ). Cell proliferation was detected using the CCK-8 assay at various time points according to the manufacturer's instructions. (B) Cell proliferation was detected in stably transfected HCC cells treated with L-asparaginase $\left(1 \mu \mathrm{ml}^{-1}\right)$. (C) The MHCCLM3-con and MHCCLM3-siASNS cells $\left(5 \times 10^{6}\right.$ cells per mouse) were inoculated into the flanks of nude mice.

L-asparaginase $\left(20 \mu \mathrm{g}^{-1}\right)$ was administered by intraperitoneal injection every other day, and the tumour growth was monitored. The error bars represent the s.d. ${ }^{\star \star} P<0.01$.

regard to L-asparaginase resistance may vary among genetic subtypes (Stams et al, 2003; den Boer et al, 2005; Stams et al, 2005). Moreover, pancreatic and ovarian tumours with low ASNS expression levels have been proposed as additional targets for L-asparaginase (Lorenzi et al, 2006, 2008; Dufour et al, 2012). In addition, one study revealed that this drug has an antiproliferative effect in $\beta$-catenin mutated HepG2 cells (Tardito et al, 2011). In our study, HCC cells with low ASNS expression were more sensitive to L-asparaginase than cells with high ASNS expression both in vitro and in vivo. This result extends those from previous studies on pancreatic and ovarian tumours and indicates that ASNS might be a potential therapeutic target in the treatment of HCC. The observations demonstrate the need to stratify patients based on the ASNS expression level in the tumour. It is proposed that HCC patients with low ASNS expression levels might benefit more from the treatment with L-asparaginase. In addition, ASNS knockdown together with L-asparaginase administration might be a new strategy for the treatment of HCC patients with high ASNS expression.

In conclusion, this study explored the effects of ASNS on tumour progression and prognosis in HCC patients for the first time. Low ASNS expression might be used to select patients for treatment with L-asparaginase. In addition, an alternative therapeutic strategy for patients with high ASNS expression was also addressed.

\section{ACKNOWLEDGEMENTS}

We thank Dong-ping Hu, Lin-na Guo, Dan Cao, Shan-hua Tang, Dan-dan Huang and Shan-na Huang for technical assistance. This 
work was supported by grants from National Natural Science Foundation of China (81001075, BWS11J036), the Funds for Creative Research Groups of China (81221061) and the State Key Project for Liver Cancer (2012ZX10002-009, 2013ZX10002-010).

\section{REFERENCES}

Amylon MD, Shuster J, Pullen J, Berard C, Link MP, Wharam M, Katz J, Yu A, Laver J, Ravindranath Y, Kurtzberg J, Desai S, Camitta B, Murphy SB (1999) Intensive high-dose asparaginase consolidation improves survival for pediatric patients with $\mathrm{T}$ cell acute lymphoblastic leukemia and advanced stage lymphoblastic lymphoma: a Pediatric Oncology Group study. Leukemia 13(3): 335-342.

Ando M, Sugimoto K, Kitoh T, Sasaki M, Mukai K, Ando J, Egashira M, Schuster SM, Oshimi K (2005) Selective apoptosis of natural killer-cell tumours by l-asparaginase. Br J Haematol 130(6): 860-868.

Appel IM, den Boer ML, Meijerink JP, Veerman AJ, Reniers NC, Pieters R (2006) Up-regulation of asparagine synthetase expression is not linked to the clinical response L-asparaginase in pediatric acute lymphoblastic leukemia. Blood 107(11): 4244-4249.

Aslanian AM, Fletcher BS, Kilberg MS (2001) Asparagine synthetase expression alone is sufficient to induce l-asparaginase resistance in MOLT4 human leukaemia cells. Biochem J 357(Pt 1): 321-328.

Chen H, Pan YX, Dudenhausen EE, Kilberg MS (2004) Amino acid deprivation induces the transcription rate of the human asparagine synthetase gene through a timed program of expression and promoter binding of nutrient-responsive basic region/leucine zipper transcription factors as well as localized histone acetylation. J Biol Chem 279(49): 50829-50839.

Cui H, Darmanin S, Natsuisaka M, Kondo T, Asaka M, Shindoh M, Higashino F, Hamuro J, Okada F, Kobayashi M, Nakagawa K, Koide H (2007) Enhanced expression of asparagine synthetase under glucose-deprived conditions protects pancreatic cancer cells from apoptosis induced by glucose deprivation and cisplatin. Cancer Res 67(7): 3345-3355.

den Boer ML, Evans WE, Pieters R (2005) TELAML1-positive ALL: a discordant genotype. Cell Cycle 4(8): 997-998.

Dong LW, Hou YJ, Tan YX, Tang L, Pan YF, Wang M, Wang HY (2011) Prognostic significance of Beclin 1 in intrahepatic cholangiocellular carcinoma. Autophagy 7(10): 1222-1229.

Dufour E, Gay F, Aguera K, Scoazec JY, Horand F, Lorenzi PL, Godfrin Y (2012) Pancreatic tumor sensitivity to plasma L-asparagine starvation. Pancreas 41(6): 940-948.

El-Serag HB (2011) Hepatocellular carcinoma. N Engl J Med 365(12): 1118-1127.

Ferlay J, Shin HR, Bray F, Forman D, Mathers C, Parkin DM (2010) Estimates of worldwide burden of cancer in 2008: GLOBOCAN 2008. Int J Cancer 127(12): 2893-2917.

Gong SS, Basilico C (1990) A mammalian temperature-sensitive mutation affecting G1 progression results from a single amino acid substitution in asparagine synthetase. Nucleic Acids Res 18(12): 3509-3513.

Greco A, Ittmann M, Basilico C (1987) Molecular cloning of a gene that is necessary for G1 progression in mammalian cells. Proc Natl Acad Sci USA 84(6): 1565-1569.

Haskell CM (1981) L-Asparaginase: human toxicology and single agent activity in nonleukemic neoplasms. Cancer Treat Rep 65(Suppl 4): 57-59.

Hutson RG, Kitoh T, Moraga Amador DA, Cosic S, Schuster SM, Kilberg MS (1997) Amino acid control of asparagine synthetase: relation to asparaginase resistance in human leukemia cells. Am J Physiol 272(5 Pt 1): C1691-C1699.

Iwamoto S, Mihara K, Downing JR, Pui CH, Campana D (2007) Mesenchymal cells regulate the response of acute lymphoblastic leukemia cells to asparaginase. J Clin Invest 117(4): 1049-1057.

Kilberg MS, Barbosa-Tessmann IP (2002) Genomic sequences necessary for transcriptional activation by amino acid deprivation of mammalian cells J Nutr 132(7): 1801-1804.

Lorenzi PL, Llamas J, Gunsior M, Ozbun L, Reinhold WC, Varma S, Ji H, Kim H, Hutchinson AA, Kohn EC, Goldsmith PK, Birrer MJ, Weinstein JN (2008) Asparagine synthetase is a predictive biomarker of L-asparaginase activity in ovarian cancer cell lines. Mol Cancer Ther 7(10): 3123-3128.
Lorenzi PL, Reinhold WC, Rudelius M, Gunsior M, Shankavaram U, Bussey KJ, Scherf U, Eichler GS, Martin SE, Chin K, Gray JW, Kohn EC, Horak ID, Von Hoff DD, Raffeld M, Goldsmith PK, Caplen NJ, Weinstein JN (2006) Asparagine synthetase as a causal, predictive biomarker for L-asparaginase activity in ovarian cancer cells. Mol Cancer Ther 5(11): 2613-2623.

Okada S, Hongo T, Yamada S, Watanabe C, Fujii Y, Ohzeki T, Horikoshi Y, Ito T, Yazaki M, Komada Y, Tawa A (2003) In vitro efficacy of 1-asparaginase in childhood acute myeloid leukaemia. $\mathrm{Br} J$ Haematol 123(5): 802-809.

Prager MD, Bachynsky N (1968) Asparagine synthetase in asparaginase resistant and susceptible mouse lymphomas. Biochem Biophys Res Commun 31(1): 43-47.

Pui CH, Relling MV, Campana D, Evans WE (2002) Childhood acute lymphoblastic leukemia. Rev Clin Exp Hematol 6(2): 161-180, discussion 200-2.

Richards NG, Kilberg MS (2006) Asparagine synthetase chemotherapy. Annu Rev Biochem 75: 629-654.

Richards NG, Schuster SM (1998) Mechanistic issues in asparagine synthetase catalysis. Adv Enzymol Relat Areas Mol Biol 72: 145-198.

Shariff MI, Cox IJ, Gomaa AI, Khan SA, Gedroyc W, Taylor-Robinson SD (2009) Hepatocellular carcinoma: current trends in worldwide epidemiology, risk factors, diagnosis and therapeutics. Expert Rev Gastroenterol Hepatol 3(4): 353-367.

Sircar K, Huang H, Hu L, Cogdell D, Dhillon J, Tzelepi V, Efstathiou E, Koumakpayi IH, Saad F, Luo D, Bismar TA, Aparicio A, Troncoso P, Navone N, Zhang W (2012) Integrative molecular profiling reveals asparagine synthetase is a target in castration-resistant prostate cancer. Am J Pathol 180(3): 895-903.

Stams WA, den Boer ML, Beverloo HB, Meijerink JP, Stigter RL, van Wering ER, Janka-Schaub GE, Slater R, Pieters R (2003) Sensitivity to $\mathrm{L}$-asparaginase is not associated with expression levels of asparagine synthetase in t(12;21) + pediatric ALL. Blood 101(7): 2743-2747.

Stams WA, den Boer ML, Holleman A, Appel IM, Beverloo HB, van Wering ER, Janka-Schaub GE, Evans WE, Pieters R (2005) Asparagine synthetase expression is linked with L-asparaginase resistance in TEL-AML1-negative but not TEL-AML1-positive pediatric acute lymphoblastic leukemia. Blood 105(11): 4223-4225.

Tardito S, Chiu M, Uggeri J, Zerbini A, Da Ros F, Dall'Asta V, Missale G, Bussolati O (2011) L-Asparaginase and inhibitors of glutamine synthetase disclose glutamine addiction of beta-catenin-mutated human hepatocellular carcinoma cells. Curr Cancer Drug Targets 11(8): 929-943.

Tezuka K, Nakayama H, Honda K, Suzumiya J, Oshima K, Kitoh T, Ishii E (2002) Treatment of a child with myeloid/NK cell precursor acute leukemia with L-asparaginase and unrelated cord blood transplantation. Int J Hematol 75(2): 201-206.

Verma N, Kumar K, Kaur G, Anand S (2007) L-asparaginase: a promising chemotherapeutic agent. Crit Rev Biotechnol 27(1): 45-62.

Wang Q, Tan YX, Ren YB, Dong LW, Xie ZF, Tang L, Cao D, Zhang WP, Hu HP, Wang HY (2011) Zinc finger protein ZBTB20 expression is increased in hepatocellular carcinoma and associated with poor prognosis. $B M C$ Cancer 11: 271.

Yokoyama H, Yamamoto J, Tohmiya Y, Yamada MF, Ohguchi H, Ohnishi Y, Okitsu Y, Fukuhara N, Ohba-Ohtsuka R, Kohata K, Ishizawa K, Kameoka J, Harigae H (2010) Allogeneic hematopoietic stem cell transplant following chemotherapy containing 1 -asparaginase as a promising treatment for patients with relapsed or refractory extranodal natural killer/T cell lymphoma, nasal type. Leuk Lymphoma 51(8): 1509-1512.

Zwaan CM, Kaspers GJ, Pieters R, Hahlen K, Janka-Schaub GE, van Zantwijk CH, Huismans DR, de Vries E, Rots MG, Peters GJ, Jansen G, Creutzig U, Veerman AJ (2002) Different drug sensitivity profiles of acute myeloid and lymphoblastic leukemia and normal peripheral blood mononuclear cells in children with and without Down syndrome. Blood 99(1): 245-251.

This work is published under the standard license to publish agreement. After 12 months the work will become freely available and the license terms will switch to a Creative Commons AttributionNonCommercial-Share Alike 3.0 Unported License.

Supplementary Information accompanies this paper on British Journal of Cancer website (http://www.nature.com/bjc) 